\title{
Hepatic function in workers occupationally exposed to carbon tetrachloride
}

\author{
John A Tomenson, Charles E Baron, John J O'Sullivan, John C Edwards,
} Michael D Stonard, Robin J Walker, Deborah M Fearnley

ICI Epidemiology

Unit, PO Box 7,

Brunner House,

Winnington,

Northwich, Cheshire

CW8 4DJ

$\mathrm{J}$ A Tomenson

Personnel

Department,

Occupational Health

Section, Clwyd

County Council, Shire

Hall, Mold, Clwyd

CH7 6NB

C E Baron

Ashling Occupational Health, Ashling

House, Works Lane,

Lostock Gralam,

Northwich, Cheshire

CW9 7FA

J J O'Sullivan

Health and Safety

Department, British

Steel, Swinden House,

Moorgate, Rotherham

S60 3AR

J C Edwards

Zeneca Central

Toxicology

Laboratory, Alderley

Park, Macclesfield,

Cheshire SK10 4TJ

M D Stonard

Walton Hospital, Rice Lane, Liverpool

L9 1AE

R J Walker

Occupational Health

Department, $H$

Heinz and Company,

Kitt Green, Wigan,

Lancashire

D M Fearnley

Correspondence to:

Dr J A Tomenson, ICI

Epidemiology Unit, PO Box

7, Brunner House,

Winnington, Northwich,

Cheshire CW8 4DJ.

Accepted 28 April 1995

\begin{abstract}
Objectives-To identify any differences in hepatic function between workers exposed to carbon tetrachloride and controls, and to identify the best variable with which to examine any effects.
\end{abstract}

Methods-In a cross sectional study of hepatic function in workers occupationally exposed to carbon tetrachloride, 135 exposed employees were compared with 276 non-exposed controls. The exposed group was taken from three sites in the north west of England and the control group included non-exposed workers from one of these sites and another site located nearby. Demographic and alcohol consumption data were collected from both groups by questionnaire. Each member of the study group was allotted a notional estimated exposure to carbon tetrachloride, calculated from historic personal monitoring data and job category. A fasting sample of blood was taken from all participants and analysed for a variety of biochemical and haematological variables. The techniques of univariate and multivariate analysis of variance were used to investigate the effect on biochemical and haematological indices of a range of factors.

Results-Multivariate analysis of variance of four core liver function variables, alanine transaminase, aspartate transaminase, alkaline phosphatase, and $\gamma$-glutamyl transferase, showed a significant difference between exposed and non-exposed workers. The univariate analyses identified increases in only alkaline phosphatase and $\gamma$-glutamyl transferase within the exposed group and these did not show a significant dose-response relation. Univariate analysis of variance did show effects of alcohol and age on several variables. Significant differences between exposed and control groups for three haematological variables, haemoglobin, packed cell volume, and red blood count, were thought not to be due to the effects of exposure. Clinical review of exposed subjects with abnormal results did not show clinically evident disease that could have been associated with exposure to carbon tetrachloride. Also, a follow up study conducted three years after the cross sectional study at the site with highest exposures to carbon tetrachloride showed no evidence of any fur- ther changes in liver function variables. Conclusions-The most sensitive statistical methods have shown significant differences in the liver function variables measured between people exposed to carbon tetrachloride and the control group. The interpretation of the data collected was that these differences may be due to exposure to carbon tetrachloride but this was not clearly shown. Furthermore, the changes found have not given rise to any clinical disease.

(Occup Environ Med 1995;52:508-514)

Keywords: occupational exposure; hepatic function; carbon tetrachloride

Carbon tetrachloride has been known for many years to be toxic to the liver. In animal experiments it has been shown to produce hepatic damage including necrosis and fatty degeneration in various species. ${ }^{12}$ Many cases of human over exposure leading to liver damage have been documented. ${ }^{3-6}$ These have in general been cases of acute overexposure to massive levels of carbon tetrachloride, whereas studies of long term exposure to lower levels contain little information about the magnitude of exposure to carbon tetrachloride and are in general, inadequate in answering questions related to assessment of health risk. ${ }^{7-10}$

Experiments on laboratory animals have shown minor effects to occur in liver tissue on repeated daily exposure to vapour at concentrations as low as 10 parts per million (ppm). ${ }^{12}$ At the time of the study, the occupational exposure limit in the United Kingdom was set at $10 \mathrm{ppm}$ ( 8 hour time weighted average). The threshold limit value set by the American Conference of Industrial Hygienists was 5 $\mathrm{ppm}^{11}$ and the internal hygiene standard recommended by the Occupational Health Department within ICI Chemicals and Polymers ( $C$ and $P$ ) was also set at $5 \mathrm{ppm}$. In the years preceding the study, compliance with this figure has not always been achieved at ICI $C$ and $P$ plants where occupational exposure to carbon tetrachloride occurs.

Because the liver is one of the target organs for carbon tetrachloride, monitoring of biological effects has formed part of the medical surveillance of workers exposed to carbon tetrachloride in the past. The monitoring of liver function tests has involved the assay of a 
single enzyme, alanine transaminase with a full liver function screen on workers who have shown an abnormality in this variable. In recent years, workers with potential exposure to carbon tetrachloride have had periodic measurements of several plasma enzymes. The data obtained from this biological surveillance have generally been used on an individual basis to identify either people who have underlying liver pathology and who are thus at greater risk from working in this environment, or to those who may be more sensitive to the effects of carbon tetrachloride and who are showing abnormalities in these tests due to exposure.

The plasma enzyme assays carried out in recent years have the advantage that they have been well tried and tested in clinical practice. An increase in measured enzyme activities may be due to a variety of causes. For example, it has been postulated that cellular damage in the liver or enzyme induction may result in increased enzyme activity after exposure to certain liver toxins. ${ }^{12}{ }^{13}$ The main disadvantage is that raised enzymes are not all organ specific and this may cause occasional diagnostic problems in clinical practice.

The measurement of total bile acids in serum may be a more sensitive indicator of hepatic function and has the advantage of being organ specific. Measurement of bile acids has not been standard clinical practice, however, and interpretation of high results might present difficulties.

The objective of the study was primarily to identify any difference in hepatic function between a work group with occupational exposure to carbon tetrachloride and a control group, which might indicate an adverse effect of exposure to carbon tetrachloride on liver function. In the event of such an effect being detected, it was also intended to investigate whether it was related to clinically detectable liver disease. A secondary objective was to identify which plasma measurements are the most sensitive indicators of any effect of carbon tetrachloride on liver function that may exist. As the testing of hepatic function necessitated the collection of a blood sample, it was decided to measure haematological variables although there was no previous evidence of changes in haematological variables after inhalation of carbon tetrachloride.

\section{Subjects and methods}

\section{STUDY DESIGN}

This was a cross sectional study that compared biochemical and haematological variables in two groups of workers in a chemical plant. The study group consisted of process, maintenance, and other workers occupationally exposed to carbon tetrachloride and the control group consisted of process, maintenance, and other workers with no occupational exposure to carbon tetrachloride.

A short questionnaire was given to all potential study and control group members in advance of the study and was used to select eligible participants. It was also used to ensure that study and control groups were well matched for demographic details (age, height, weight, and type of job) and alcohol consumption.

Participation in the study was voluntary and the study group contained 135 workers, $83 \%$ of those eligible for inclusion. The control group was drawn from a target population of 370 employees who worked at two sites. At one site, a series of communication exercises were held and workers were encouraged to volunteer and complete the short questionnaire. At the second site, workers were sent a letter describing the study and a copy of the short questionnaire. Three hundred and twenty five employees completed the short questionnaire and $88 \%$ of those selected to participate on the basis of their responses to the short questionnaire, agreed to take part. The overall participation in the control group was $276(77 \%)$.

\section{EXPOSED GROUP}

Subjects in the exposed study group were volunteers drawn from three plants in the north west of England belonging to ICI C and P. To qualify for inclusion in the study group employees were required to work on one of the processes with potential exposure to carbon tetrachloride either full time (in the case of process personnel and dedicated maintenance personnel) or on a regular basis (in the case of other maintenance personnel).

\section{CONTROL GROUP}

A control population was chosen from employees of ICI C and P who worked on plants where there was no risk of exposure to carbon tetrachloride or other hepatotoxic chemicals. Control subjects came from one of the sites that provided workers for the exposed group and a further site located nearby where carbon tetrachloride is not handled. Workers were excluded from the control group if they had worked in or on any of a predefined list of workplaces within ICI where there was a potential for exposure to carbon tetrachloride or other known hepatotoxins, during the previous five years.

The study was scheduled to start in November 1986 but after a two week period of sample collection (about 60 subjects) there was a problem with availability of controls due to plant breakdown. In view of this it was decided to restart the study in February 1987 and the rest of the samples were taken during a period of about eight weeks.

\section{QUESTIONNAIRE}

An extensive questionnaire was given to each member of the study and control groups. The questionnaire was given by one occupational health nursing officer trained for this purpose. The data obtained on the questionnaire included age, height, weight, job description, plant, hobbies, medical history, and a detailed alcohol history. Also, the length of service in a job exposed to carbon tetrachloride was obtained for the exposed workers. 
BIOCHEMICAL AND HAEMATOLOGICAL MEASUREMENTS

All members of the study and control groups had a blood sample taken on the day on which they completed the questionnaire. This blood sample was taken after the subject had not eaten or drank beverages containing milk, sugar, or alcohol for the previous 12 hours. The sample comprised $15 \mathrm{ml}(10 \mathrm{ml}$ in a lithium heparinised tube, $4 \mathrm{ml}$ in a plain glass tube for serum, and $1 \mathrm{ml}$ in an EDTA tube for a full blood count). Samples were transported to the ICI central toxicology laboratory for analysis on the morning of collection. To minimise any effect of laboratory variation, blood samples were taken from a roughly constant ratio of study and control group subjects on each day.

The variables measured on plasma, serum, or EDTA samples consisted of alanine transaminase, aspartate transaminase, alkaline phosphatase, $\gamma$ glutamyl transferase, glutamate dehydrogenase, $5^{\prime}$ nucleotidase, total bile acids, cholesterol, and triglycerides.

The haematological variables consisted of haemoglobin, packed cell volume, mean corpuscular volume, red blood count, mean corpuscular haemoglobin concentration, platelets, white blood count, lymphocyte, monocyte, eosinophil, neutrophil, and basophil counts.

Bile acids were measured with a commercial radioimmunoassay and other biochemical variables were measured with either a Vitatron PA800 analyser or a Kone CD analyser. Haematological variables were measured with an ELT 800 analyser.

\section{EXPOSURE}

Each member of the study group was allotted a notional estimated exposure to carbon tetrachloride that was calculated from historical personal monitoring data for each job category. According to this estimate, study group members were allotted to an exposure category (high, medium, or low).

Most work groups had historical personal monitoring data and the mean of these results was calculated and the group categorised. The

Table 1 Alcohol consumption of exposed and control populations

\begin{tabular}{|c|c|c|}
\hline Alcohol consumption & Control $(\%)$ & Exposed $(\%)$ \\
\hline $\begin{array}{l}\text { Low: } \\
\text { Never drink } \\
12 \text { Units no more than } 1-2 \text { times/week } \\
37 \text { Units no more than } 2-3 \text { times/month } \\
>8 \text { Units no more than once/month }\end{array}$ & $26 \cdot 5$ & $23 \cdot 0$ \\
\hline $\begin{array}{l}\text { Medium: } \\
1-2 \text { Units at least 3-4 times/week } \\
57 \text { Units } 3-4 \text { times } / \text { week } \\
>8 \text { Units } 1-2 \text { times } / \text { week }\end{array}$ & $26 \cdot 9$ & 21.5 \\
\hline $\begin{array}{l}\text { High: } \\
\text { 3-4 Units at least 3-4 times/week } \\
\text { 5-7 Units 3-4 times/week } \\
>8 \text { Units } 1-2 \text { times/week }\end{array}$ & $27 \cdot 3$ & $28 \cdot 9$ \\
\hline $\begin{array}{l}\text { Very high: } \\
57 \text { Units every day } \\
>8 \text { Units at least 3-4 times/week }\end{array}$ & $19 \cdot 6$ & $26 \cdot 7$ \\
\hline
\end{tabular}

low category contained those with mean results of $1 \mathrm{ppm}$ or less, the medium category included groups with mean results from more than $1 \mathrm{ppm}$ to $3 \mathrm{ppm}$ and the high category, those with mean results of $4 \mathrm{ppm}$ or more. For groups or workers where no monitoring had taken place, categorisation was allotted by judgement of likely exposure from comparison with other groups. This judgement was made by a professional industrial hygienist in association with each plant manager. The appendix shows a summary of the distribution of results on which the categorisation was based.

Members of the study group were also categorised according to length of time in the job ( $<1$ year, $1-5$ years, and $>5$ years)

\section{STATISTICAL METHODS}

The techniques of univariate and multivariate analysis of variance were used to investigate the effect on biochemical and haematological indices of a range of factors, in particular that attributable to exposure to carbon tetrachloride. For certain biochemical and haematological measurements a logarithmic transformation gave closer agreement with the assumptions of the analysis of variance model-that is, normally distributed errors and a linear model. All analyses of these variables were performed on the logarithmically transformed measurements. The SAS package was used to fit the univariate and multivariate analysis of variance models. ${ }^{1+}$

Linear models were fitted to either the raw or logarithmically transformed data. The terms in the models included exposure category, age, sampling time (first or second phase) and a measure of alcohol intake based on the quantity and frequency of consumption. The possibility of a synergistic reaction between exposure to carbon tetrachloride and alcohol consumption was examined by including an interaction term between the two factors in the linear model.

For each exposure category, further comparisons were made between workers at the four sites. Also, a multivariate analysis of variance was performed for the four variables alkaline phosphatase, aspartate transaminase, alanine transaminase, and $\gamma$-glutamyl transferase, with the same linear models as the univariate analysis.

The means presented in tables are least square means. ${ }^{15}$ These means correct for imbalance in the numbers of workers in the different categories when broken down by the factors present in the analysis of variance model.

As well as comparing mean levels of the biochemical and haematological variables in the exposed and non-exposed groups, the spread of results was also compared. For each variable a normal range was constructed for the non-exposed workers, which ranged from the $2.5 \%$ quantile up to the $97.5 \%$ quantile. The percentage of exposed and non-exposed workers lying above and below the range were calculated for each variable. 
Table 2 Exposure effects-means (SEM) † of selected biochemical and haematological indices for different exposure categories

\begin{tabular}{|c|c|c|c|c|}
\hline & None & Low & Medium & High \\
\hline & Mean (SEM) & Mean (SEM) & Mean (SEM) & Mean (SEM) \\
\hline Alanine transaminase $f(\mathrm{mU} / \mathrm{ml})$ & $20.54(1.03)$ & $20 \cdot 35(1.08)$ & $20 \cdot 82(1.05)$ & $19.39(1.06)$ \\
\hline Aspartate transaminase $\dagger(\mathrm{mU} / \mathrm{ml})$ & $16.48(1.02)$ & $15 \cdot 25(1 \cdot 05)$ & $15 \cdot 88(1.04)$ & $15.62(1.04)$ \\
\hline Alkaline phosphatase $(\mathrm{mU} / \mathrm{ml})$ & $125 \cdot 79(1.02)$ & $122 \cdot 20(1.05)$ & $137 \cdot 10^{\star}(1 \cdot 04)$ & $135 \cdot 10(1 \cdot 04)$ \\
\hline$\gamma$-Glutamyl transferasef (mU/ml) & $26.89(1.05)$ & $26 \cdot 89(1 \cdot 11)$ & $33 \cdot 17 \star(1 \cdot 08)$ & $31.50(1.08)$ \\
\hline Total bile acidst $(\mu \mathrm{mol} / \mathrm{l})$ & $1.06(1.06)$ & $1.00(1.14)$ & $1.25(1 \cdot 10)$ & $1 \cdot 28(1 \cdot 10)$ \\
\hline $5^{\prime}$-Nucleotidase $(\mathrm{mU} / \mathrm{ml})$ & $5.89(1.03)$ & $6.54(1.08)$ & $6.25(1.06)$ & $5.75(1.06)$ \\
\hline Glutamate dehydrogenaset $(\mathrm{mU} / \mathrm{ml})$ & $3.00(1.05)$ & $3.26(1 \cdot 10)$ & $3 \cdot 57^{\star}(1 \cdot 07)$ & $2.98(1.07)$ \\
\hline Haemoglobin $(\mathrm{g} / \mathrm{dl})$ & $15.97(0.08)$ & $15.60(0.19)$ & $15 \cdot 39^{\star \star \star}(0 \cdot 14)$ & $15 \cdot 71(0 \cdot 14)$ \\
\hline Packed cell volume & $48.54(0.23)$ & $47 \cdot 32^{\star}(0 \cdot 54)$ & $47 \cdot 32^{\star \star}(0 \cdot 39)$ & $48.05(0.41)$ \\
\hline Red blood count $\left(\times 10^{12} / 1\right)$ & $5.61(0.03)$ & $5.50(0.08)$ & $5 \cdot 47^{\star}(0.06)$ & $5.50(0.06)$ \\
\hline
\end{tabular}

${ }^{\star} \mathrm{P} \leqslant 0.05 ;{ }^{\star \star} \mathrm{P} \leqslant 0.01 ;{ }^{\star \star \star} \mathrm{P} \leqslant 0.001 ; v$ control group.

† Geometric means (SEM) are presented for variables analysed after a logarithmic transformation. ${ }^{16}$

\section{Results}

The study and control groups were well matched for age, height, weight, work patterns and alcohol consumption. The ages of subjects in the exposed and control groups were roughly normally distributed with means between 40 and 41 and ranges of $18-63$ and 17-62, respectively. Virtually all control (97\%) and exposed (98\%) subjects were current drinkers. Table 1 shows the drinking habits and the alcohol consumption as measured by the variable measuring the quantity and frequency of alcohol consumption.

Preliminary analyses were first performed incorporating an interaction term between exposure to carbon tetrachloride and alcohol consumption. No evidence of such an effect was found in these analyses and the term was dropped from the analyses presented below. Univariate analyses of variance for all 21 of the biochemical and haematological variables showed significant differences between exposed and non-exposed workers for only three variables, haemoglobin $(P<0.001)$, packed cell volume and red blood count $(\mathbf{P}<$ $0.01)$. None of these variables showed any significant differences between exposed workers in the three exposure categories.

Significant relations with alcohol consumption were found for total bile acids ( $P<$ $0.001), \gamma$ glutamyl transferase $(P<0.01)$, red blood count, mean corpuscular volume, and triglycerides $(P<0.05)$. There were also significant differences for several variables between samples taken in November 1986 and those taken in spring 1987 . These differences were particularly obvious for the haematological variables. Several variables showed significant relations with age. The strongest relations with age were seen for $\gamma$-glutamyl transferase, cholesterol, and triglycerides $(P<0.001)$ but mean corpuscular volume $(P<0.01)$ and aspartate transaminase, $5^{\prime}$ nucleotidase, red blood count, and neutrophil count $(P<0.05)$ were also related to age.

Table 2 shows mean results by exposure category for the targeted variables alanine transaminase, aspartate transaminase, alkaline phosphatase, $\gamma$-glutamyl transferase, total bile acids, 5'-nucleotidase, and glutamate dehydrogenase and those variables for which there was a significant difference between exposed and non-exposed workers, haemoglobin, packed cell volume, and red blood count.

The multivariate analysis of variance of the variables alkaline phosphatase, aspartate transaminase, alanine transaminase, and $\gamma$ glutamyl transferase showed a significant difference $(P<0.05)$ between exposed and non-exposed workers. In the exposed group there were no significant differences between different exposure categories. The univariate analyses of variance of these four variables did not show significant differences between exposed and non-exposed workers. Pairwise comparisons showed a significant increase ( $P$ $<0.05)$ in the concentrations of alkaline phosphatase and $\gamma$-glutamyl transferase in the medium exposure group and a comparable, but non-significant increase in the high exposure group (table 2). There were no similar patterns in the concentrations of aspartate transaminase and alanine transaminase.

Table 3 shows mean results by alcohol category for alanine transaminase, aspartate transaminase, alkaline phosphatase, $\gamma$-glutamyl transferase and total bile acids and the other variables that showed a significant alcohol

Table 3 Alcohol effects-means (SEM) † of selected biochemical and haematological indices for different alcohol consumptions

\begin{tabular}{|c|c|c|c|c|}
\hline & Low & Medium & High & Very high \\
\hline & Mean (SEM) & Mean (SEM) & Mean (SEM) & Mean (SEM) \\
\hline Alanine transaminase $(\mathrm{mU} / \mathrm{ml})$ & $20.40(1.05)$ & $21 \cdot 10(1 \cdot 04)$ & $20 \cdot 75(1.04)$ & $19 \cdot 22(1.04)$ \\
\hline Aspartate transaminase $(\mathrm{mU} / \mathrm{ml})$ & $15 \cdot 76(1.03)$ & $16 \cdot 19(1.03)$ & $16 \cdot 12(1.03)$ & $16.04(1.03)$ \\
\hline Alkaline phosphatase $(\mathrm{mU} / \mathrm{ml})$ & $128.23(1.03)$ & $126.38(1.03)$ & $126.84(1.03)$ & $132.69(1.03)$ \\
\hline$\gamma$-Glutamyl transferasef $(\mathrm{mU} / \mathrm{ml})$ & $24.60(1.07)$ & $27.97(1.06)$ & $30.05^{\star \star}(1.06)$ & $32 \cdot 32^{\star \star \star}(1 \cdot 06)$ \\
\hline Total bile acids $f(\mu \mathrm{mol} / \mathrm{l})$ & $1.02(1.08)$ & $0.94(1.07)$ & $1.19(1.07)$ & $1 \cdot 35^{\star \star}(1.08)$ \\
\hline Triglyceridest $(\mathrm{mg} / \mathrm{dl})$ & $125.08(1.07)$ & $122 \cdot 87(1.06)$ & $139 \cdot 16(1.06)$ & $149.77^{\star}(1 \cdot 06)$ \\
\hline Mean corpuscular volume & $86 \cdot 11(1 \cdot 01)$ & $85.73(1.01)$ & $87 \cdot 22(1.01)$ & $87 \cdot 59^{\star}(1 \cdot 01)$ \\
\hline Red blood count $\left(\times 10^{12} /\right)$ & $5.60(0.05)$ & $5.61(0.04)$ & $5 \cdot 48^{\star}(0.04)$ & $5.52(0.05)$ \\
\hline
\end{tabular}

${ }^{\star} \mathrm{P} \leqslant 0.05 ;{ }^{\star \star} \mathrm{P} \leqslant 0.01 ;{ }^{\star \star \star} \mathrm{P} \leqslant 0.001 ; v$ low group

t Geometric means (SEMs) are presented for variables analysed after a logarithmic transformation. ${ }^{16}$ 
Table 4 Normal ranges derived from results of control group with percentages above and below in exposed and non-exposed groups

\begin{tabular}{|c|c|c|c|c|c|c|c|c|}
\hline \multirow[b]{3}{*}{ Variable (with manufacturers range) } & \multirow{2}{*}{\multicolumn{2}{|c|}{ Range }} & \multicolumn{3}{|c|}{ Non-exposed } & \multicolumn{3}{|c|}{ Exposed } \\
\hline & & & \multirow{2}{*}{$\begin{array}{l}\text { Below } \\
(\%)\end{array}$} & \multirow{2}{*}{$\begin{array}{l}\text { Above } \\
(\%)\end{array}$} & \multirow[b]{2}{*}{$n$} & \multirow{2}{*}{$\begin{array}{l}\text { Below } \\
(\%)\end{array}$} & \multirow{2}{*}{$\begin{array}{l}\text { Above } \\
(\%)\end{array}$} & \multirow[b]{2}{*}{$n$} \\
\hline & Lower & Upper & & & & & & \\
\hline Alanine transaminase $(\mathrm{mU} / \mathrm{ml})(<29)$ & $9 \cdot 6$ & $40 \cdot 0$ & $2 \cdot 3$ & $2 \cdot 7$ & 262 & 1.6 & $7 \cdot 8$ & 129 \\
\hline Aspartate transaminase $(\mathrm{mU} / \mathrm{ml})(<25)$ & $11 \cdot 0$ & $30 \cdot 4$ & $3 \cdot 8$ & $2 \cdot 3$ & 262 & $6 \cdot 2$ & $1 \cdot 6$ & 129 \\
\hline Alkaline phosphatase $(\mathrm{mU} / \mathrm{ml})(<170)$ & $80 \cdot 0$ & $206 \cdot 0$ & $2 \cdot 7$ & $3 \cdot 0$ & 263 & $0 \cdot 8$ & $4 \cdot 7$ & 129 \\
\hline$\gamma$-Glutamyl transferase $(\mathrm{mU} / \mathrm{ml})(<50)$ & $10 \cdot 6$ & $68 \cdot 0$ & $2 \cdot 3$ & $3 \cdot 0$ & 263 & 0.8 & $10 \cdot 9$ & 129 \\
\hline Total bile acids $(\mu \mathrm{mol} / \mathrm{l})(<6)$ & $0 \cdot 3$ & $3 \cdot 3$ & $6 \cdot 2$ & $2 \cdot 5$ & 242 & 1.6 & $4 \cdot 1$ & 122 \\
\hline 5'-Nucleotidase (mU/ml) $(2-10)$ & $3 \cdot 0$ & $13 \cdot 0$ & $6 \cdot 8$ & $3 \cdot 0$ & 263 & $5 \cdot 4$ & $3 \cdot 1$ & 129 \\
\hline Glutamate dehydrogenase $(\mathrm{mU} / \mathrm{ml})(<4)$ & $1 \cdot 6$ & $8 \cdot 0$ & $2 \cdot 3$ & $3 \cdot 0$ & 263 & 3.9 & $7 \cdot 0$ & 129 \\
\hline Haemoglobin $(\mathrm{g} / \mathrm{dl})(14 \cdot 0-18 \cdot 0)$ & $13 \cdot 9$ & $17 \cdot 6$ & $3 \cdot 4$ & $2 \cdot 3$ & 264 & 3.9 & $3 \cdot 1$ & 130 \\
\hline Packed cell volume (39-52) & $40 \cdot 2$ & $54 \cdot 3$ & $2 \cdot 7$ & $2 \cdot 7$ & 264 & $1 \cdot 5$ & $0 \cdot 0$ & 130 \\
\hline Red blood count $\left(\times 10^{12} / 1\right)(4 \cdot 5-6 \cdot 3)$ & 4.5 & $6 \cdot 3$ & $2 \cdot 3$ & $2 \cdot 3$ & 264 & 3.9 & 0.8 & 129 \\
\hline
\end{tabular}

effect, triglycerides and mean corpuscular volume. The significance of comparisons of the medium, high, and very high consumption groups with the low consumption group are also given.

For each exposure category (high, medium, low, or unexposed) a comparison was made between workers at the four sites. These analyses showed no significant differences between biochemical and haematological variables in workers at the four sites.

Table 4 shows the results of the normal range analysis for the targeted variables and those showing a significant difference in concentrations between exposed and nonexposed workers. The ranges are presented together with the percentage less than or equal to the lower limit or greater than or equal to the upper limit. The reference ranges supplied by the manufacturers of the tests are also included for comparison. The proportion of exposed workers above the upper limit was significantly raised for two variables, alanine transaminase $\quad(P<0.05)$ and $\gamma$-glutamyl transferase $(P<0.001)$. There was little difference between the proportions of exposed and non-exposed workers below the lower limits of the haematological variables, haemoglobin, packed cell volume, and red blood count.

\section{Discussion}

The finding of a significant difference between exposed and control groups in the multivariate analysis of alanine transaminase, aspartate transaminase, alkaline phosphatase, and $\gamma$-glutamyl transferase is consistent with the excess of abnormal results in the exposed group for two of these variables, alanine transaminase and $\gamma$ glutamyl transferase (table 4). The univariate analysis of variance did not show significant differences between the exposed and non-exposed workers in these four variables, but there was a suggestion of a dose response for alkaline phosphatase and $\gamma$-glutamyl transferase.

The lack of a significant dose-response effect may be due to imprecision in the exposure ranking of each worker. Unfortunately, few measurements were available for the lower exposure groups as the monitoring strategy mainly targets the higher exposure groups. In general, however, workers in the high group will have had greater exposure than those in the medium group who in turn have had greater exposure than those in the low group. Alternatively the finding of a lack of dose-response effect but a difference between the group exposed to carbon tetrachloride and the control group could have been due to something other than carbon tetrachloride.

The comparison of alcohol consumption in the two groups (table 1) shows that the exposed group admitted to drinking five to seven units of alcohol every day or eight or more units at least three or four times a week (very high category) more frequently than the control group. The results shown in table 3 of mean values of several liver function variables according to alcohol consumption are broadly in line with those that would have been expected from a clinical viewpoint. This finding gives some confidence to the accuracy of the alcohol data.

From a theoretical understanding of the metabolism of carbon tetrachloride and alcohol one might expect that alcohol and carbon tetrachloride would have a synergistic effect on liver function. ${ }^{17-19}$ This was tested by including an interaction term between alcohol and exposure in the linear model. No synergistic effect could be detected.

To determine the extent to which the effect of exposure on the multivariate analysis of liver function could have been related to clinically detectable liver disease, all participants from both study and control groups with one or more results in excess of 3 SDs outside the control group mean were reviewed in a clinical gastroenterology department by a specialist. The result of this review was that one case of liver disease (as defined clinically by the gastroenterologist) was identified but this could not be explained by exposure to carbon tetrachloride at work. Another study subject was found to have non-Hodgkin's lymphoma and one control had haemochromatosis.

Before the study there was an expectation that total bile acids might represent a more sensitive test of liver function than the more commonly used variables of alanine transaminase, aspartate transaminase, alkaline phosphatase, and $\gamma$-glutamyl transferase. In the event, the two variables that seem to have been most affected were alkaline phosphatase and $\gamma$-glutamyl transferase. These two variables 
contributed most to the differences noted in the multivariate analysis although when analysed on a univariate basis, the difference between exposed and control groups did not reach significance. It could be argued that the appearance of enzymes such as alkaline phosphatase, alanine transaminase, aspartate transaminase, or $\gamma$-glutamyl transferase in plasma at higher activities reflects an increase in cell turnover or cellular leakage of these enzymes. In contrast, total bile acids are specific endogenous materials that are synthesised and secreted by the liver and can be used as a functional index of the liver. An explanation of the results of this study could thus be that there has been some enzyme leakage from cells without measurable deficit in function.

The haematology results presented a different picture to those of the liver function tests. Differences between exposed and control groups noted in the univariate analysis for haemoglobin, packed cell volume, and red blood count were not accompanied by an equivalent increase in the number of abnormally low results in the exposed group but rather by a decrease in the number of abnormality high results for two of the variables (table 4). There is no theoretical basis for a reduction of haemoglobin, packed cell volume, or red blood count as a result of exposure to carbon tetrachloride. Indeed, Loyke in a study of the effects of subcutaneous carbon tetrachloride on normotensive SpragueDawley rats showed an increase in red blood cell count in treated animals and no significant change in packed cell volume or haemoglobin. ${ }^{20}$ Finally there is no indication of any exposure-effect relation for these variables (table 2).

It seems unlikely that the differences between exposed and control groups in the three haematological variables were caused by exposure to carbon tetrachloride but there is no obvious explanation. There were significant differences in many haematological variables between samples taken in November 1986 and those taken in February or March 1987 and there is a possibility that some sea- sonal or laboratory effect could have introduced a systematic bias. ${ }^{21}$ The later results were analysed separately and were consistent with the overall result.

Biochemical and haematological variability of workers from different sites could have caused exposure like effects. The hygiene results (appendix) show, for instance, that there were no workers in the highest exposure category at one site. There was no evidence to suggest that the biochemical and haematological variables differed between workers in the same category at different sites, although the numbers of workers in the different exposure categories were sometimes too small to perform sensitive comparisons between the four sites.

Despite reservations about the accuracy of the assessment of exposure to carbon tetrachloride, there was no evidence of effects of clear clinical significance on the liver function of workers exposed to carbon tetrachloride at the levels indicated. Nevertheless, there is the possibility that exposure to carbon tetrachloride was responsible for some of the effects seen in liver function enzymes. Before the study started, considerable efforts were being made to identify and implement improvements in plant and procedures to reduce exposure. These were continued at the three plants involved.

As a postscript to the study, a follow up study was conducted at one of the sites three years after the cross sectional study. A large proportion of the workers at this site had been categorised in the high exposure group in the cross sectional study but considerable reductions in exposures at this site had since been achieved. Changes in haematological and biochemical variables were compared between 26 exposed workers and 43 unexposed workers who had participated in the cross sectional study. There was clear evidence of differences in laboratory procedure between the laboratories who had performed the testing of blood samples in the cross sectional and follow up studies. The changes in variables over the three year period were remarkably consistent

APPENDIX: Distribution of personal monitoring results for exposure to carbon tetrachloride in three plants

\begin{tabular}{|c|c|c|c|c|c|}
\hline \multirow[b]{2}{*}{ Category } & \multirow[b]{2}{*}{ Results mean } & \multicolumn{3}{|c|}{ Number of subjects (number of results) } & \multirow[b]{2}{*}{ Total } \\
\hline & & Plant 1 & Plant 2 & Plant 3 & \\
\hline Low: & $\begin{array}{l}\text { Measured range: } \\
<1 \mathrm{ppm} \\
1 \mathrm{ppm} \\
\text { Estimated } \\
\text { Total }\end{array}$ & $\begin{array}{l}0 \\
0 \\
6\end{array}$ & $\begin{array}{l}0 \\
0 \\
6\end{array}$ & $\begin{array}{l}0 \\
17(52) \\
11\end{array}$ & $\begin{array}{r}0 \\
17 \\
23 \\
40\end{array}$ \\
\hline Medium: & $\begin{array}{c}\text { Measured range: } \\
1 \cdot 1-1.9 \mathrm{ppm} \\
2-2.9 \mathrm{ppm} \\
3-3.9 \mathrm{ppm} \\
\text { Estimated } \\
\text { Total }\end{array}$ & $\begin{array}{l}4(76) \\
8(190) \\
4(1) \\
8\end{array}$ & $\begin{array}{l}0 \\
2(26) \\
1(5) \\
1\end{array}$ & $\begin{array}{r}0 \\
0 \\
0 \\
26\end{array}$ & $\begin{array}{r}4 \\
10 \\
5 \\
35 \\
54\end{array}$ \\
\hline High: & $\begin{array}{l}\text { Measured range: } \\
4-5.9 \mathrm{ppm} \\
6-7.9 \mathrm{ppm} \\
8-9.9 \mathrm{ppm} \\
10-11.9 \mathrm{ppm} \\
\text { Estimated } \\
\text { Total }\end{array}$ & $\begin{array}{l}12(588) \\
12(407) \\
4(135) \\
0 \\
2\end{array}$ & $\begin{array}{l}2(11) \\
2(16) \\
12(56) \\
15(173) \\
0\end{array}$ & $\begin{array}{l}0 \\
0 \\
0 \\
0 \\
0\end{array}$ & $\begin{array}{r}14 \\
14 \\
16 \\
15 \\
2 \\
61\end{array}$ \\
\hline
\end{tabular}


in the exposed and unexposed groups. The follow up study has provided no evidence of any further changes in biochemical and haematological indices since the cross sectional study.

Finally, a comparison of the ranges calculated from the control group with the reference ranges supplied from the manufacturers of the biochemical tests show that there were some substantial differences between the two sets of ranges (table 4). In general the control group (and the study group) had higher average results for all the liver function variables than would have been expected from the reference ranges supplied with the tests. The reason for this difference is not completely clear, although it could be due to the use of hospital or laboratory populations to formulate reference ranges. If this is the case, these populations are clearly not comparable with a group of working men in the north west of England and it does emphasise the importance of having a proper control group in this type of study.

We express our particular gratitude to Sisters Debbie Fearnley, Doreen Evans, Win Ashcroft, and Margaret Riley for their role in local organisation, data collection, and venesection. Thanks also to Sue Braithwaite for her work in data coordination and to Angela Benson for her contribution to the preparation of the report.

1 Adams EM, Spencer HC, Rowe VK, et al. Vapor toxicity of carbon tetrachloride determined by experiments on laboratory animals. Arch Ind Hyg Occup Med 1952;6 50-66.

2 Prendergast JA, Jones RA, Jenkins LJ, et al. Effects on experimental animals of longterm inhalation of trichloroethylene, carbon tetrachloride, 1,1,1-trichloroethane, dichlorodiflouromethane and 1,1-dichloroethylene. Toxicol Appl Pharmacol 1967;10:270-89.
3 Campbell CB, Collins DM, Van Tongeren A. Serum bile acids and other liver function tests in hepatocellula damage from carbon tetrachloride ingestion. NZ Med $f$ 1980;91:381-4

4 Dellian VL, Wittgens $H$. Labour hygiene experience with carbon tetrachloride in railroad workshops. Zentrab Arbeitsmed 1962;12:216-23.

5 Kazantziz G, Bomford RR. Dyspepsia due to inhalation of carbon tetrachloride vapour. Lancet 1960;i:360-2.

6 Lachnit V, Pietschmann H. Activity of serum-glutamicoxaloacetic-transaminase and aldolase in workers exposed to halogenated hydrocarbons. Ind Med Surg 1960;29:523-5.

7 Rabes U. Medical studies on long-time carbon tetrachloride exposed workers. Wissenschaftliche Zeitschrift Martin Luther Universitat Halle Wittenberg 1972;21:73-80.

8 Saric M, Prpic-Majic D, Beritic T. Activity of serum transaminase in workers exposed to carbon tetrachloride. Arh Hig Rada Toksikol 1962;13:19-27.

9 Smyth HF, Smyth HF Jr, Carpenter CP. The chronic toxicity of carbon tetrachloride; animal exposure and field icity of carbon tetrachloride; animal exposur. 7 Ind Hyg Toxicol 1936;18:277-98.

10 Barnes R, Jones RC. Carbon tetrachloride poisoning. Am Ind Hyg Assoc F 1967;28:557-61.

11 American Conference of Government Industrial Hygienists. Documentation of the threshold limit values and biological exposure indices, 5th ed Cincinatti: ACGIH 1986.

12 Misslbeck NG, Campbell TC, Roe DA. Increase in hepatic gamma-glutamyl transferase activity following chronic ethanol intake in combination with a high fat diet. Biochem Pharmacol 1986;35:399-404.

13 Teschke R, Ramen J, Nenefiend M, et al. Alcoholic liver disease associated with increased gamma-glutamyl transferase activities in serum and liver. Adv Exp Med Biol ferase activities in

14 SAS Institute. The users guide version 5 th ed. North Carolina: SAS Institute, 1985

15 Searle SR, Speed SH, Milliken GA. Population marginal means in the linear model: an alternative to least squar means. The American Statistician 1980;34:216-21.

16 Kirkwood TBL. Geometric means and measures of dispersion. Biometrics 1979;35:908-9.

17 Folland DS, Schaffer W, Gunn HE, et al. Carbon tetrachloride toxicity potentiated by isopropyl alcohol. $\mathscr{f} A M A$ 1976;236:1853-6.

18 Strubelt O, Obermeier F, Siegers CP, et al. Increased carbon tetrachloride hepatotoxicity after low-level ethanol bon tetrachloride hepatotoxicity after low-

19 Wei E, Wong LCK, Hine CH. Potentiation of carbon tetrachloride hepatotoxicity by ethanol and cold. Toxicol Appl Pharmacol 1971;18:329-34.

20 Loyke HF. Haematological and blood pressure studies in cell treated rats. $\mathcal{F}$ Environ Pathol Toxicol Oncol 1986 7:1-8.

21 Lee CJ, Lawler GS, Panemangalore $M$. Nutritional status of middle-aged and elderly females in Kentucky in two seasons: part 2. Haematological parameters. $7 \mathrm{Am}$ Coll Nutr $1987 ; 6: 217-22$.

\section{Correspondence and editorials}

Occupational and Environmental Medicine welcomes correspondence relating to any of the material appearing in the journal. Results from preliminary or small scale studies may also be published in the correspondence column if this seems appropriate. Letters should be not more than 500 words in length and contain a minimum of references. Tables and figures should be kept to an absolute minimum. Letters are accepted on the understanding that they may be subject to editorial revision and shortening.

The journal also publishes editorials which are normally specially commissioned. The Editor welcomes suggestions regarding suitable topics; those wishing to submit an editorial, however, should do so only after discussion with the Editor. 